\title{
Níveis de Treonina em Rações para Leitões dos 6 aos 15 kg $^{1}$
}

\section{Nair Elizabeth Barreto Rodrigues ${ }^{2}$, Juarez Lopes Donzele ${ }^{3}$, Rita Flávia Miranda de Oliveira ${ }^{3}$, Aloísio Soares Ferreira ${ }^{3}$, Darci Clementino Lopes ${ }^{3}$, Moacir Rodrigues Filho ${ }^{2}$}

\begin{abstract}
RESUMO - Foram utilizados 75 suínos com peso inicial médio de 5,8 $\pm 0,4 \mathrm{~kg}$, com o objetivo de avaliar níveis de treonina em rações para leitões com alto potencial genético para deposição de carne magra dos 6 aos $15 \mathrm{~kg}$. Foi usado o delineamento experimental de blocos ao acaso com cinco tratamentos (níveis de treonina), cinco repetições e três animais por unidade experimental. Os tratamentos corresponderam a uma ração basal com $18 \%$ PB e 1,108\% lisina total, suplementada com cinco níveis de L-treonina, resultando em dietas com níveis de 0,$682 ; 0,732 ; 0,782 ; 0,832 ;$ e $0,883 \%$ de treonina total. Observou-se variação quadrática para ganho de peso diário (GDP), que aumentou até o nível de $0,77 \%$, e para consumo de ração (CR), que aumentou até o nível estimado de $0,73 \%$. Os níveis de treonina também influenciaram de forma quadrática a conversão alimentar (CA), que melhorou até o nível de $0,82 \%$. A relação da lisina digestível verdadeira:treonina digestível verdadeira, no nível que proporcionou os melhores resultados de CA, correspondeu a 100:73. Concluiuse que leitões com alto potencial genético para carne magra dos 6 aos $15 \mathrm{~kg}$ exigem $0,77 \%$ de treonina total na ração para máximo ganho de peso e $0,82 \%$ para melhor conversão alimentar.
\end{abstract}

Palavras-chave: fase inicial, desempenho, aminoácido

\section{Levels of Threonine in Diets for Piglets from 6 to $15 \mathrm{~kg}$}

\begin{abstract}
Seventy five piglets with average initial weight of $5.8 \pm .4 \mathrm{~kg}$ were used to evaluate the levels of threonine in the diets for piglets from 6 to $25 \mathrm{~kg}$ with high genetic potential for lean deposition. A randomized blocks design, with five treatments(threonine levels), five replicates and three animals by experimental unit was used. The treatments consisted of basal diet with $18 \%$ crude protein (CP) and $1.108 \%$ total lysine, supplemented with five levels of L-threonine, resulting in diets with $(0.682,0.732,0.782,0.832$, and $0.883 \%$ of total threonine. It was observed quadratic variation for average daily weight gain, that increased up to $.77 \%$ threonine, and for feed intake (FI), that increased up to $0.73 \%$ of threonine. Feed:gain ratio, that increased up to $0.82 \%$ of threonine, was also influenced by the threonine levels. The true digestible lysine:true digestible threonine ratio, at the level with the best F/G results, was 100:73. It was concluded that for swine from 6 to $15 \mathrm{~kg}$ with high genetic potential for lean meat met $0.77 \%$ total threonine in the diet for maximum weight gain and $0.82 \%$ for the best feed:gain ratio.
\end{abstract}

Key Words: amino acid, initial phase, performance

\section{Introdução}

Com o intuito de melhorar a produtividade do rebanho por meio do aumento do número de desmamados/porca/ano, nas últimas décadas, a idade de desmama dos leitões reduziu de 60 para entre 17 e 24 dias de idade.

Com a redução na idade do desmame dos leitões, as rações para estes animais passaram a ser mais elaboradas, principalmente, no que se refere à qualidade da proteína, quanto à sua digestibilidade e composição em aminoácidos, fatores estes que podem influenciar o apetite e, conseqüentemente, a taxa de crescimento dos animais.

Assim, um dos maiores avanços no entendimento das exigências protéicas dos suínos foi o estabelecimento do conceito de proteína ideal, em que os aminoácidos, essenciais e não-essenciais são fornecidos, em quantidades adequadas, às exigências dos animais, nas diferentes fases de crescimento.

Como a treonina é usualmente o segundo ou terceiro aminoácido limitante em rações práticas de suínos e pode ser o primeiro limitante, quando lisina sintética é adicionada à ração (SALDANA et al., 1994), o estabelecimento da sua exigência pelos leitões é de fundamental importância para assegurar o bom desempenho dos animais.

Considerando que o requerimento de treonina total proposto para suínos na fase inicial varia muito entre as fontes de referência, $0,78 \%$ para leitões de

\footnotetext{
1 Parte da tese de Mestrado apresentada à UFV para obtenção do título "Magister Scientiae".

2 Professor da Escola Agrotécnica Federal de Santa Tereza, ES

3 Professor da UFV. E.mail: donzele@mail.ufv.br; flavia@mail.ufv.br
} 
5 a $15 \mathrm{~kg}$ (ROSTAGNO et al., 2000), 0,86\% para leitões de 5 a $10 \mathrm{~kg}$ e $0,74 \%$ para leitões de 10 a $20 \mathrm{~kg}$ (NATIONAL RESEARCH COUNCIL - NRC, 1998), desenvolveu-se este trabalho para determinar a exigência de treonina para leitões na fase inicial (6 a $15 \mathrm{~kg}$ ).

\section{Material e Métodos}

O experimento foi conduzido no Setor de Suinocultura do Departamento de Zootecnia, do Centro de Ciências Agrárias da Universidade Federal de Viçosa - MG, no período de 27 de março a 16 de maio de 2000.

Foram utilizados 75 leitões mestiços (Landrace $\mathrm{x}$ Large White) com peso inicial médio de 5,8 $\pm 0,4 \mathrm{~kg}$, distribuídos em um delineamento experimental de blocos casualizados, com cinco tratamentos, cinco repetições, em que a baia com três animais foi a unidade experimental. Na formação dos blocos, foram levados em consideração o peso inicial e o grau de parentesco dos animais.

Os animais foram alojados em creches metálicas suspensas, com piso e laterais telados, providas de comedouros semi-automáticos e bebedouros tipo chupeta, localizadas em galpão de alvenaria, com piso de concreto, teto de madeira rebaixado e janelas basculantes nas laterais.

A temperatura no interior do galpão foi registrada diariamente usando termômetro de máxima e mínima, colocado na parte mediana do galpão a uma altura correspondente à dos animais. As temperaturas ambientais máxima e mínima médias, durante o período experimental, foram $26,4 \pm 1,8^{\circ} \mathrm{C}$ e $22,8 \pm 2,6^{\circ} \mathrm{C}$, respectivamente, e a umidade relativa, de $74,8 \pm 7,8 \%$.

As rações experimentais (Tabela 1), isoenergéticas com $18 \% \mathrm{~PB}$, foram formuladas à base de milho, farelo de soja e soro de leite em pó, suplementadas com minerais, vitaminas e cinco níveis de L-treonina, proporcionando uma relação treonina digestível:lisina digestível de 58, 63, 68, 73 e $78 \%$, respectivamente; os demais aminoácidos ficaram, no mínimo, acima da relação aminoacídica da proteína ideal, preconizada por WANG e FULLER (1989, 1990). O fornecimento das rações experimentais e de água foi à vontade.
Os animais foram pesados no início e final do experimento, para determinação do ganho de peso, enquanto as rações foram pesadas sempre que fornecidas, juntamente com as respectivas sobras, para determinação do consumo. A duração do experimento foi, em média, de 27 dias, quando os animais atingiram peso de $15,2 \pm 1,6 \mathrm{~kg}$.

As análises bromatológicas dos ingredientes das rações foram realizadas no Laboratório de Nutrição do Departamento de Zootecnia da UFV, conforme metodologia descrita por SILVA (1990).

No final do experimento, após um período de 24 horas de jejum, um animal de cada unidade experimental foi abatido por sangramento, depilado e eviscerado. As carcaças inteiras, incluindo pés e cabeça, foram pesadas e as meias-carcaças, armazenadas em câmara fria e, posteriormente, trituradas em "cuter" comercial de $30 \mathrm{HP}$ e 1775 revoluções por minuto. Após homogeneização, foram retiradas amostras de aproximadamente $1,0 \mathrm{~kg}$, as quais foram conservadas a $-12^{\circ} \mathrm{C}$, para análises posteriores.

Um adicional de sete animais, com peso médio de $5,95 \pm 0,21 \mathrm{~kg}$, foi abatido, seguindo-se o mesmo procedimento de abate dos animais no final do experimento, para determinação da composição da carcaça dos animais no início do experimento e posterior determinação das taxas de deposição de proteína e gordura, conforme técnica descrita por DONZELE et al. (1992).

As amostras foram colocadas em estufa com ventilação forçada a $60^{\circ} \mathrm{C}$, por 96 horas, sendo posteriormente pré-desengorduradas pelo método a quente, por quatro horas, em extrator tipo "Soxhlet". As amostras pré-secas e prédesengorduradas foram moídas em moinho de bola e acondicionadas em vidros, para análises posteriores.

As análises estatísticas das variáveis de desempenho foram realizadas utilizando o programa Sistema de Análises Estatísticas e Genéticas SAEG (UNIVERSIDADE FEDERAL DE VIÇOSA - UFV, 1997). A estimativa da exigência de treonina foi feita com base nos resultados de ganho de peso, conversão alimentar, taxas de deposição de gordura e proteína, utilizando-se os modelos linear e, ou, quadrático. 
Tabela 1 - Composição das rações experimentais (\%)

Table 1 - Composition of experimental diets (\%)

\begin{tabular}{|c|c|c|c|c|c|}
\hline \multirow[t]{2}{*}{$\begin{array}{l}\text { Ingredientes } \\
\text { Ingredients }\end{array}$} & \multicolumn{5}{|c|}{$\begin{array}{l}\text { Níveis de treonina }(\%) \\
\text { Levels of threonine }\end{array}$} \\
\hline & 0,68 & 0,73 & 0,78 & 0,83 & 0,88 \\
\hline $\begin{array}{l}\text { Milho }(7,69 \%)^{3} \\
\text { Corn }\end{array}$ & 59,175 & 59,175 & 59,175 & 59,175 & 59,175 \\
\hline $\begin{array}{l}\text { Corn } \\
\text { Açúcar }\end{array}$ & 2,248 & 2,197 & 2,146 & 2,095 & 2,044 \\
\hline $\begin{array}{l}\text { Sugar } \\
\text { Farelo de soja }(45,5 \%)^{3} \\
\text { Soybean oil }\end{array}$ & 23,200 & 23,200 & 23,200 & 23,200 & 23,200 \\
\hline $\begin{array}{l}\text { Soro de leite em pó } \\
\text { Dried skim milk }\end{array}$ & 7,000 & 7,000 & 7,000 & 7,000 & 7,000 \\
\hline $\begin{array}{l}\text { Ácido glutâmico } \\
\text { Glutamic acid }\end{array}$ & 2,662 & 2,662 & 2,662 & 2,662 & 2,662 \\
\hline $\begin{array}{l}\text { Fosfato bicálcico } \\
\text { Dicalcium phosphate }\end{array}$ & 1,895 & 1,895 & 1,895 & 1,895 & 1,895 \\
\hline $\begin{array}{l}\text { Calcário } \\
\text { Limestone }\end{array}$ & 0,535 & 0,535 & 0,535 & 0,535 & 0,535 \\
\hline $\begin{array}{l}\text { L-Lisina } \mathrm{HCl} \\
\text { L-lysine } \mathrm{HCl}\end{array}$ & 0,297 & 0,297 & 0,297 & 0,297 & 0,297 \\
\hline $\begin{array}{l}\text { DL-Metionina }(99 \%) \\
\text { DL-Methionine }\end{array}$ & 0,113 & 0,113 & 0,113 & 0,113 & 0,113 \\
\hline $\begin{array}{l}\text { L-Treonina } \\
\text { L-Threonine }\end{array}$ & 0,000 & 0,051 & 0,102 & 0,153 & 0,204 \\
\hline $\begin{array}{l}\text { Sal } \\
\text { Salt }\end{array}$ & 0,305 & 0,305 & 0,305 & 0,305 & 0,305 \\
\hline $\begin{array}{l}\text { Óleo vegetal } \\
\text { Vegetal oil }\end{array}$ & 2,400 & 2,400 & 2,400 & 2,400 & 2,400 \\
\hline $\begin{array}{l}\text { Suplemento mineral } \\
\text { Mineral mix }\end{array}$ & 0,050 & 0,050 & 0,050 & 0,050 & 0,050 \\
\hline $\begin{array}{l}\text { Suplemento vitamínico }{ }^{2} \\
\text { Vitamin mix }\end{array}$ & 0,120 & 0,120 & 0,120 & 0,120 & 0,120 \\
\hline $\begin{array}{l}\text { Total } \\
\text { Composição calculada }{ }^{4}(\%) \\
\text { Calculated composition }\end{array}$ & 100,00 & 100,00 & 100,00 & 100,00 & 100,00 \\
\hline $\begin{array}{l}\text { Proteína bruta } \\
\text { Crude protein }\end{array}$ & 18,00 & 18,00 & 18,00 & 18,00 & 18,00 \\
\hline $\begin{array}{l}\text { Energia digestível }(\mathrm{kcal} / \mathrm{kg}) \\
\text { Digestible energy }\end{array}$ & 3403 & 3401 & 3399 & 3397 & 3395 \\
\hline $\begin{array}{l}\text { Fibra bruta } \\
\text { Crude fiber }\end{array}$ & 2,575 & 2,575 & 2,575 & 2,575 & 2,575 \\
\hline $\begin{array}{l}\text { Cálcio } \\
\text { Calcium }\end{array}$ & 0,800 & 0,800 & 0,800 & 0,800 & 0,800 \\
\hline $\begin{array}{l}\text { Fósforo total } \\
\text { Total phosphorus }\end{array}$ & 0,650 & 0,650 & 0,650 & 0,650 & 0,650 \\
\hline $\begin{array}{l}\text { Lisina total } \\
\text { Total lysine }\end{array}$ & 1,108 & 1,108 & 1,108 & 1,108 & 1,108 \\
\hline $\begin{array}{l}\text { Lisina digestível }{ }^{5} \\
\text { Digestible lysine }\end{array}$ & 1,000 & 1,000 & 1,000 & 1,000 & 1,000 \\
\hline $\begin{array}{l}\text { Treonina total } \\
\text { Total threonine }\end{array}$ & 0,682 & 0,732 & 0,782 & 0,832 & 0,883 \\
\hline $\begin{array}{l}\text { Treonina digestível } \\
\text { Digestible threonine }\end{array}$ & 0,580 & 0,630 & 0,680 & 0,730 & 0,781 \\
\hline
\end{tabular}

\footnotetext{
${ }_{1}^{1}$ Mistura de minerais - Roligomix, Suínos (Roche) - Fe, 90 g; Cu, 10 g; Co, 2 g; Mn, 40 g; Zn, 2 g e Excipiente q.s.p. 500 g.

${ }^{2}$ Mistura vitamínica - Rovimix, Suínos Crescimento (Roche) - Vit. A, 10.000.000 U.I.; Vit $D_{3}, 1.000 .000$ U.I.; Vit E, 15.000 U.I.; Vit.B - $_{1}, 0$ g; Vit. B 6 , $1,5 \mathrm{~g}$; Vit. $\mathrm{B}_{12}, 22,0 \mathrm{mg}$; Ácido nicotínico (Nicotinic acid), 22,0 g; Ácido pantotênico (Pantotenic acid), 12 g; Vit. K 3 , 25 g; Ácido fólico (Folic acid), 0,6 g; Biotina (Biotin), 0,1 g; Vit.C, 30,0 g; Antioxidante (Antioxidant), $30 \mathrm{~g}$ e Excipiente q.s.p., $1.000 \mathrm{~g}$.

${ }^{3}$ Valores analisados no Laboratório de Nutrição Animal do DZO/UFV, de acordo com a metodologia descrita por SILVA (1990).

${ }^{4}$ Composição calculada segundo ROSTAGNO et al. (2000), com exceção da proteína bruta.

5 Digestibilidade verdadeira.

3 Values calculated at the Animal Nutrition Lab - DZO - UFV, according to SILVA (1990) methodology.

4 Composition calculated according to ROSTAGNO (1996), except for crude protein.

5 True digestibility.
} 


\section{Resultados e Discussão}

Os resultados de ganho de peso diário (GPD), consumo de ração diário (CRD) e conversão alimentar (CA) de leitões com alto potencial genético para deposição de carne magra, dos 6 aos $15 \mathrm{~kg}$, encontram-se na Tabela 2.

Foi observado efeito dos níveis de treonina total da ração $(\mathrm{P}<0,04)$ sobre o ganho de peso dos animais, que variou de forma quadrática, tendo aumentado até o nível de $0,77 \%$ (Figura 1). Variação quadrática do ganho de peso de leitões entre 6 e $16 \mathrm{~kg}$, em razão do aumento do nível de treonina da ração $(0,60$ a 0,76\%), também foi observado por SALDANA et al. (1994), que, no entanto, estimaram em $0,69 \%$ o nível de treonina total para máximo ganho. Por outro lado, LEWIS e PEO JR. (1986), avaliando níveis de treonina $(0,53$ a $0,83 \%)$ para leitões de 5 a $15 \mathrm{~kg}$, observaram aumento linear no ganho de peso dos animais.

Considerando que, no conceito da proteína ideal, a lisina é o aminoácido utilizado como referência para expressar as proporções dos demais aminoácidos essenciais (EMMERT e BAKER, 1997), a variação nos níveis de lisina das rações experimentais utilizadas nos diferentes trabalhos pode, entre outros fatores, justificar a variação dos resultados.

No nível em que se estimou o melhor resultado de ganho de peso $(0,77 \%)$, a relação treonina digestível:lisina digestível calculada correspondeu a $67 \%$. Este resultado está coerente com os dados do trabalho desenvolvido por CHUNG e BAKER (1992), que, comparando rações elaboradas com base na proteína ideal preconizada pelo NRC (1988), por WANG e FULLER (1989) e pela Universidade de Illinois (IIP), para leitões de $10 \mathrm{~kg}$, constataram maior ganho de peso dos animais que receberam a ração formulada com base nas recomendações da IIP, em que a relação treonina:lisina correspondeu a $65 \%$ comparada àquela de $59 \%$ proposta pelo NRC (1988) e $72 \%$ por WANG e FULLER (1989).

Os níveis de treonina da ração influenciaram $(\mathrm{P}<0,05)$ de forma quadrática o consumo de ração, que aumentou até o nível estimado de $0,73 \%$ (Figura 2). Neste nível de treonina, a relação calculada de treonina digestível:lisina digestível correspondeu a $63 \%$.

Os dados de literatura referentes à influência da treonina sobre o consumo de ração de leitões na fase inicial são conflitantes. Enquanto SALDANA et al. (1994) observaram resposta similar àquela verificada neste trabalho e, ROSELL e ZIMMERMAN (1985), redução linear no consumo até o nível de $0,70 \%$ de treonina, LEWIS e PEO JR. (1986) e BORG et al. (1987) não constataram variação significativa no consumo de ração dos leitões, quando avaliaram níveis de treonina da ração para suínos jovens.

A variação de resultados do efeito do nível de treonina sobre o consumo de ração dos leitões, observada entre os trabalhos, pode ser explicada, em parte, pela diferença no nível de proteína utilizada nas rações experimentais. HENRY e SÉVE (1993) relataram que o excesso de treonina tendeu a causar queda na ingestão de alimento dos leitões que receberam ração com $15 \%$ PB, enquanto tendência inversa ocorreu com

Tabela 2 - Desempenho e taxas de deposição de gordura e proteína na carcaça de leitões dos 6 aos 15 kg, alimentados com ração contendo níveis crescentes de treonina

Table 2 - Performance and fat and protein deposition rates in the carcas of piglets from 6 to $15 \mathrm{~kg}$ fed diets with crescent levels of threonine

\begin{tabular}{|c|c|c|c|c|c|c|}
\hline \multirow[t]{2}{*}{$\begin{array}{l}\text { Variáveis } \\
\text { Variables }\end{array}$} & \multicolumn{5}{|c|}{$\begin{array}{c}\text { Níveis de treonina }(\%) \\
\text { Threonine levels }\end{array}$} & \multirow[t]{2}{*}{$\mathrm{CV}(\%)$} \\
\hline & 0,68 & 0,73 & 0,78 & 0,83 & 0,88 & \\
\hline $\begin{array}{l}\text { Ganho de peso }(\mathrm{g} / \text { dia })^{1} \\
\text { Weight gain }(\text { g/day) }\end{array}$ & 339 & 347 & 356 & 354 & 324 & 6,31 \\
\hline $\begin{array}{l}\text { Consumo de ração }(\mathrm{g} / \mathrm{dia})^{2} \\
\text { Feed intake (g/day) }\end{array}$ & 595 & 584 & 598 & 578 & 535 & 4,95 \\
\hline $\begin{array}{l}\text { Conversão alimentar } \\
\text { Feed:gain ratio }\end{array}$ & 1,81 & 1,72 & 1,71 & 1,65 & 1,71 & 4,54 \\
\hline $\begin{array}{l}\text { Taxas de deposição médias na carcaça } \\
\text { Average deposition rates in the carcass }\end{array}$ & 1,81 & 1,72 & 1,71 & 1,65 & 1,71 & 4,54 \\
\hline $\begin{array}{l}\text { Gordura }(\mathrm{g} / \text { dia }) \\
\text { Fat }(\text { g/day) }\end{array}$ & 41 & 37 & 38 & 37 & 38 & 12,6 \\
\hline $\begin{array}{l}\text { Proteína }(\mathrm{g} / \text { dia }) \\
\text { Protein }(\mathrm{g} / \text { day })\end{array}$ & 36 & 43 & 37 & 38 & 37 & 17,9 \\
\hline
\end{tabular}

Rev. bras. zootec., 30(6S):2033-2038, 2001 


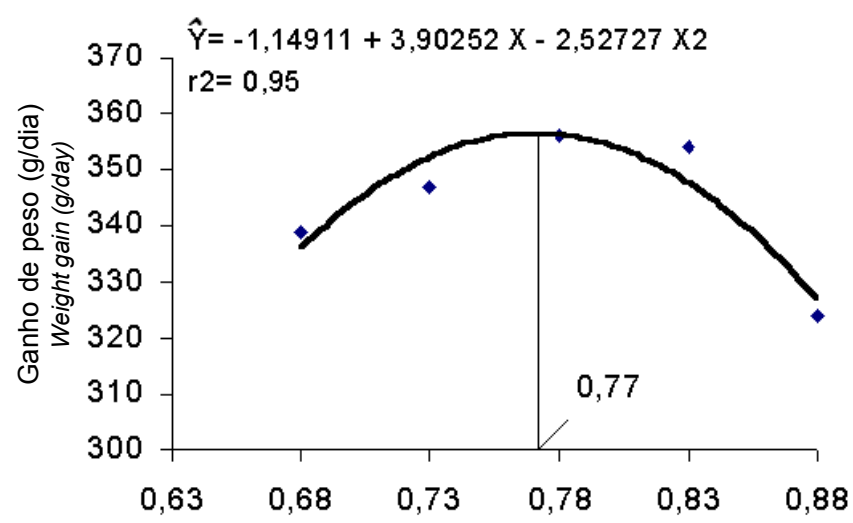

Níveis de treonina (\%)

Threonine levels

Figura 1 - Ganho de peso médio diário de leitões dos 6 aos $15 \mathrm{~kg}$, em função do nível de treonina da ração.

Figure 1 - Average daily weight gain of piglets from 6 to $15 \mathrm{~kg}$, according to the dietary levels of threonine.

os animais que receberam ração com 20\% PB.

Embora tenham variado de forma quadrática, os valores de consumo de ração nos três primeiros níveis de treonina total avaliados $(0,68 ; 0,73$ e $0,78 \%)$ foram próximos, apresentando variação de, no máximo, $2,34 \%$, enquanto nos dois maiores níveis $(0,83$ e $0,88 \%)$ as reduções corresponderam a 3,34 e $10,54 \%$, respectivamente, em relação ao maior valor de consumo obtido. Estes resultados estariam indicando a possibilidade de ter ocorrido um desequilíbrio de aminoácidos na ração do último tratamento, em razão de possível excesso de treonina. De acordo com HARPER et al. (1970), redução da ingestão de alimentos constitui uma das respostas típicas, devido ao desequilíbrio de aminoácidos na ração.

O nível de treonina que resultou em maior consumo de ração $(0,73 \%)$ ficou abaixo daquele que proporcionou melhor ganho de peso $(0,77 \%)$, o que corrobora o relato de Henry (1983), citado por HENRY e SÉVE (1993), de que o suprimento de treonina para máxima ingestão de alimento seria menor que aquele para máximo ganho.

Os níveis de treonina influenciaram $(\mathrm{P}<0,10)$ de forma quadrática a conversão alimentar que reduziu até o nível estimado de $0,82 \%$ (Figura 3 ).

Efeito quadrático do nível de treonina na ração sobre a conversão alimentar de leitões, na fase inicial de crescimento $(6,4$ a 14,4 kg), também foi observado por LEWIS e PEO JR. (1986), que, no entanto, estimaram em $0,70 \%$ o nível de treonina que proporcionou a melhor conversão. Todavia, os resultados deste trabalho estão

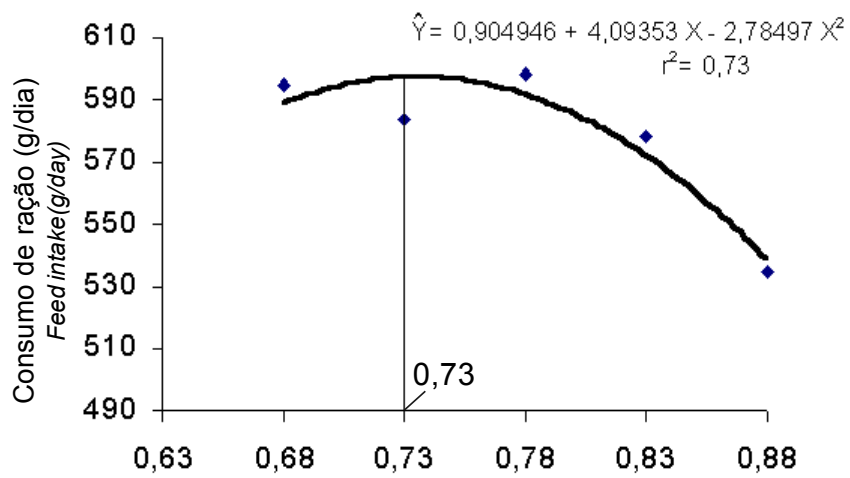

Níveis de treonina (\%)

Threonine levels

Figura 2 - Consumo médio de ração diário de leitões dos 6 aos $15 \mathrm{~kg}$, conforme o nível de treonina da ração.

Figure 2 - Average daily feed intake of piglets from 6 to $15 \mathrm{~kg}$, according to the dietary levels of threonine.

mais próximos daqueles obtido por BORG et al. (1987) e SALDANA et al. (1994), que observaram melhoria linear na conversão alimentar de leitões, em razão do aumento da concentração de treonina da ração de 0,50 para 0,78 e de 0,60 para $0,76 \%$, respectivamente.

A variação de conversão alimentar observada neste trabalho está consistente com resultados obtidos por EDMONDS e BAKER (1987), que, avaliando rações para leitões com 0,5 e $4,0 \%$ de excesso de treonina, verificaram que a eficiência alimentar melhorou linearmente, enquanto o ganho de peso e o consumo de ração reduziram em 12,5 e 20,2\%, respectivamente, evidenciando que a conversão alimentar responde positivamente a níveis mais elevados de treonina.

A relação calculada de treonina digestível:lisina digestível no nível que proporcionou melhor conversão alimentar correspondeu a $73 \%$, ficando acima daquela de $67 \%$ para máximo ganho de peso. Este resultado está coerente com o relato de ROSELL e ZIMMERMAN (1985) de que melhor resposta de eficiência alimentar é obtida com nível de treonina acima daquele que resultaria em máximo ganho de peso.

A variação de valores nos níveis de treonina que proporcionaram melhores respostas de desempenho (ganho de peso, consumo de ração e conversão alimentar), entre os trabalhos, pode estar relacionada, além da diferença do nível de proteína das rações experimentais, à diferença da digestibilidade da treonina nos alimentos utilizados na formulação das rações.

Não se observou efeito $(\mathrm{P}>0,10)$ dos níveis de 


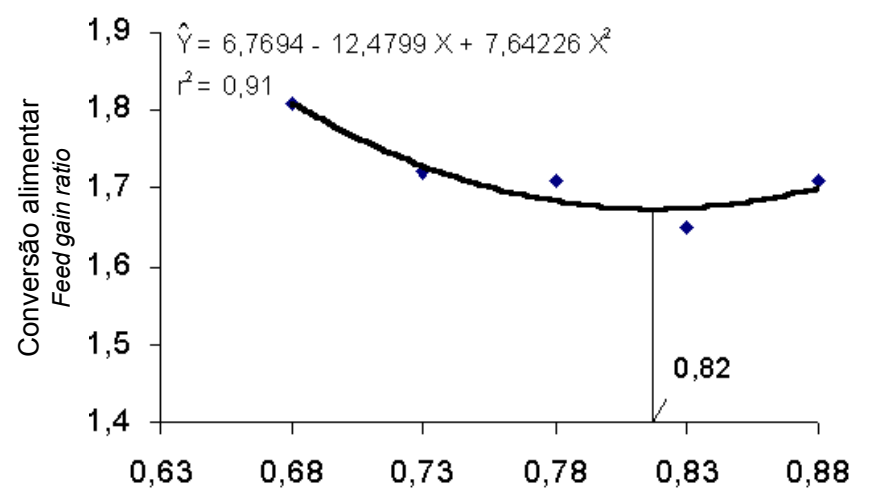

Níveis de treonina (\%)

Threonine levels

Figura 3 - Conversão alimentar de leitões dos 6 aos 15 kg, conforme o nível de treonina da ração.

Figure 3 - Feed:gain ratio of piglets from 6 to $15 \mathrm{~kg}$, according to the dietary levels of threonine.

treonina sobre a taxa de deposição de proteína na carcaça (TDP). Este resultado difere daquele obtido por ADEOLA (1995), que constatou aumento na taxa de deposição de proteína na carcaça de leitões entre 10 e $20 \mathrm{~kg}$, quando o nível de treonina da ração aumentou de 0,40 para $0,53 \%$.

A divergência entre os resultados dos trabalhos pode estar relacionada às diferenças nos níveis de treonina utilizados, que, no caso do estudo de ADEOLA (1995), foram mais baixos.

Embora não tenha variado significativamente, verificou-se que no nível de $0,73 \%$ foi obtido o maior valor absoluto de TDP, que diferiu em $16 \%$ da média dos demais tratamentos.

De forma similar à TDP, a taxa de deposição de gordura (TDG) na carcaça não foi influenciada $(\mathrm{P}>0,10)$ pela concentração de treonina da ração. No entanto, foi observado que a TDG variou em valores absolutos, de maneira inversa à TDP, entre os dois primeiros níveis avaliados, apresentando redução de $9,8 \%$.

Relação inversa entre taxa de deposição de proteína e gordura na carcaça de suínos também foi relatada por TAYLOR et al. (1982) e ADEOLA (1995).

\section{Conclusões}

Concluiu-se que leitões com alto potencial genético para deposição de carne magra, dos 6 aos $15 \mathrm{~kg}$, exigem $0,77 \%$ de treonina total na ração para máximo ganho de peso e $0,82 \%$ para melhor conversão alimentar.

\section{Referências Bibliográficas}

ADEOLA, O. 1995. Dietary lysine and threonine utilization by young pigs: efficiency for carcass growth. Journal paper $\mathrm{n}^{\circ} 14614$ of purdue University Agricultural Research Programs.

BEECH, S.A., BATTERHAM, E.S., ELLIOT, R. 1991. Utilization of ileal digestible amino acids by growing pigs: threonine. Brit. J. Nutr., 65:381-390.

BORG, B.S., LIBAL, W., WAHLSTROM, R.C. 1987. Tryptopham and threonine requirements of young pigs and their effects on serum calcium, phosphorus and zinc concentrations. J. Anim. Sci., 64:1070-1078.

CHUNG, T.K., BAKER, D.H. 1992. Ideal amino acid pattern for $10 \mathrm{~kg}$ pigs. J. Anim. Sci., 70:3102.

DONZELE, J.L., COSTA, P.M.A., ROSTAGNO, H.S. et al. 1992. Efeitos dos níveis de lisina na composição da carcaça de suínos de 5 a 15 kg. R. Soc. Bras. Zootec., 21:1091-1099.

EDMONDS, M.S., BAKER, D.H. 1987. Amino acid excess for young pigs: effects of excess methionine, tryptophan, threonine or leucine. J. Anim. Sci., 64:1664-1671.

EMMERT, J., BAKER, D.H. 1997. Use of the ideal protein concept for precision formulation of amino acid levels in broiler diets. J. Appl. Poult. Res., 6:462-470.

HARPER, A.E., BENEVENGA, N.J., WOHLHUETER, R.M. 1970. Effects of ingestion of ingestion of disproportionate amounts of amino acids. Physiological Rewies, 50:428-558.

HENRY, Y., SÉVE, B. 1993. Feed intake and dietary amino acid balance in growing pigs with special reference tolysine, tryptophan, and threonine. Pig News and Information, 14:35N-43N.

LEWIS, A.J., PEO JR., E.R. 1986. Threonine requirement of pigs weighting 5 to $15 \mathrm{~kg}$. J. Anim. Sci., 62:1617-1623.

NATIONAL RESEARCH COUNCIL - NRC. 1988. Nutrient requirements of swine. 9.ed. Washington, D.C.: National Academy Press.

NATIONAL RESEARCH COUNCIL - NRC. 1998. Nutrient requirements of swine. 10.ed., Washington, D.C.: National Academic of Sciences. 189p.

ROSELL, V.L., ZIMMERMAN, D.R. 1985. Threonine requirement of pigs weighing 5 to $15 \mathrm{~kg}$ and the effect of excess methionine in diets marginal in threonine. J. Anim. Sci., 60:480-486.

ROSTAGNO, H.S. 2000. Tabelas brasileiras para aves e suinos; composição de alimentos e exigências nutricionais. Viçosa: UFV. 141p.

SALDANA, C.I., KNABE, D.A., OWEN, K.Q. et al. 1994. Digestible threonine requirements of starter and finisher pigs. J. Anim. Sci., 72:144-150.

SILVA, D.J. 1990. Análise de alimentos (Métodos químicos e biológicos). Viçosa: UFV. 160p.

TAYLOR, A.J., COLE, D.J.A. , LEWIS, D. 1982. Amino acid requirements of growing pigs. 3. Threonine. Anim. Prod., 34:1-8.

UNIVERSIDADE FEDERAL DE VIÇOSA - UFV. 1997. Sistema de análises estatísticas e genética - SAEG. Viçosa, MG: UFV (Software).

WANG, T.C., FULLER, M.F. 1989. The optimum dietary amino acid pattern for growing pigs. 1. Experiments by aminoacid deletion. Br. J. Nut., 62:77-89.

WANG, T.C., FULLER, M.F. 1990. The effect of nutrition on the optimum dietary amino acid pattern for growing pigs. Anim. Prod., 50:155-164.

Rev. bras. zootec., 30(6S):2033-2038, 2001

Recebido em:08/02/01 Aceito em: 03/08/01 